\title{
NEOTECTÔNICA NA BACIA HIDROGRÁFICA DO MINDU - MANAUS - AMAZONAS
}

\author{
MATHEUS SILVEIRA DE QUEIROZ \\ matheussilveiradequeiroz@gmail.com \\ NELIANE DE SOUSA ALVES \\ nsalves@uea.edu.br
}

\section{RESUMO}

O objetivo desse trabalho é analisar a neotectônica na Bacia Hidrográfica do Mindu, no município de Manaus - Amazonas. Para isto, foram feitas pesquisas bibliográficas e de campo entre os anos de 2018 e 2019, observando anomalias de drenagem e fatores tectônicos que indiquem atividade neotectônica na bacia como lineamentos morfoestruturais e basculamentos tectônicos. Analisando os fatores neotectônicos de lineamentos, anomalias de drenagem (curvas anômalas) e basculamento da Bacia Hidrográfica do Mindu é possível afirmar, usando como base os dados obtidos e a literatura disponível, que a bacia foi submetida à atividade neotectônica, possivelmente durante o cenozoico. Isso impactou na morfologia da rede de drenagem como um todo e, principalmente, no padrão do canal principal da bacia, o igarapé do Mindu.

PALAVRAS-CHAVE: Neotectônica; Bacias Hidrográficas Urbanas; Rede de Drenagem.

\section{ABSTRACT}

The objective of this research is to analyze the neotectonics in the Mindu Basin, in the municipality of Manaus - Amazonas. For this, bibliographic and field research was carried out between 2018 and 2019, observing drainage anomalies and tectonic factors that indicate neotectonic activity in the basin such as morphostructural linings and tectonic stipulations. Analyzing the neotectonic factors of linings, drainage anomalies (anomalous curves) and stipulations of the Mindu Basin it is possible to affirm, based on the data obtained and the available literature, that the basin was submitted to the activity neotectonic, possibly during Cenozoic. This impacted the morphology of the drainage network as a whole and, mainly, on the pattern of the main channel of the basin, the igarapé of Mindu.

KEY-WORDS: Neotectonic; Urban Basins; Drainage Network. 


\section{INTRODUÇÃO}

O termo neotectônica foi introduzido pela primeira vez por Obruchev (1948) para classificar movimentos tectônicos que ocorreram entre o fim do terciário e no quaternário. Com a evolução do aparato científico o termo foi mais bem desenvolvido, Mörner (1993) considera que não há necessidade de um limite inferior de idade para classificar a neotectônica, porém Vita-Finzi (1986 apud SUGUIU, 2010) afirma deveria tratar das deformações ocorridas durante o cenozoico tardio.

O primeiro autor a indagar sobre a atividade neotectônica na bacia hidrográfica amazônica foi Sternberg (1950) em seu clássico trabalho "Vales tectônicos na planície Amazônica?". O autor afirma que existe paralelismo em sentido NE-SW e NW-SE, entre os principais rios da área analisada que englobam os rios Negro (na altura do arquipélago fluvial de Anavilhanas), Preto da Eva, Urubu, Tarumã-Mirim, Manacapuru, além de feições como o padrão retilíneo dos rios, inflexões em ângulo reto ou em cotovelo, e a formação de feixes paralelos desses segmentos.

Stevaux e Latrubesse (2017) afirmam que a neotectônica juntamente com as mudanças climáticas são os principais fatores da metamorfose dos sistemas fluviais. Os efeitos do tectonismo podem ser observados tanto em escala regional, através de grandes falhas ou escarpas de falha, tanto no local, com pequenas alterações e deformações nas rochas. Essas alterações modificam a morfologia dos canais podendo interferir no gradiente, no fornecimento de sedimentos, e no nível de base, introduzindo mudanças de padrão e rupturas no perfil longitudinal dos rios. Logo, o estudo da neotectônica no contexto das bacias hidrográficas é importante para determinar as alterações ocorridas na morfogênese. Portanto, este trabalho tem como objetivo analisar a neotectônica em uma bacia hidrográfica na área urbana do município de Manaus, como objetivos específicos entender a influência tectônica na morfologia da rede de drenagem da bacia; caracterizar os tipos de alterações morfo-estruturais devido à neotectônica atuante na bacia.

\subsection{LOCALIZAÇÃO DA ÁREA DE ESTUDO E CARACTERIZAÇÃO GEOLÓGICA REGIONAL}

A cidade de Manaus fica localizada nas proximidades da confluência dos rios Negro e Solimões, onde forma-se o rio Amazonas, na microrregião denominada de Baixo Amazonas. 0 município possui, segundo estimativas de 2019 do Instituto Brasileiro de Estatística e Geografia - IBGE, uma população de 2.145.444 habitantes. Manaus possui uma ampla rede de drenagem e sua área urbana comporta quatro bacias hidrográficas principais: São Raimundo, Tarumã, Puraquequara e Educandos, além de diversos afluentes que compõe a malha hídrica da metrópole. A Bacia Hidrográfica do Mindu (Figura 1), foco da pesquisa, faz parte da Bacia Hidrográfica do São Raimundo, e está localizada $100 \%$ na área urbana da cidade com uma área de $66 \mathrm{~km}^{2}$. O igarapé do Mindu, rio principal da bacia, possui uma extensão de 18,2 km (QUEIROZ et al., 2019). 


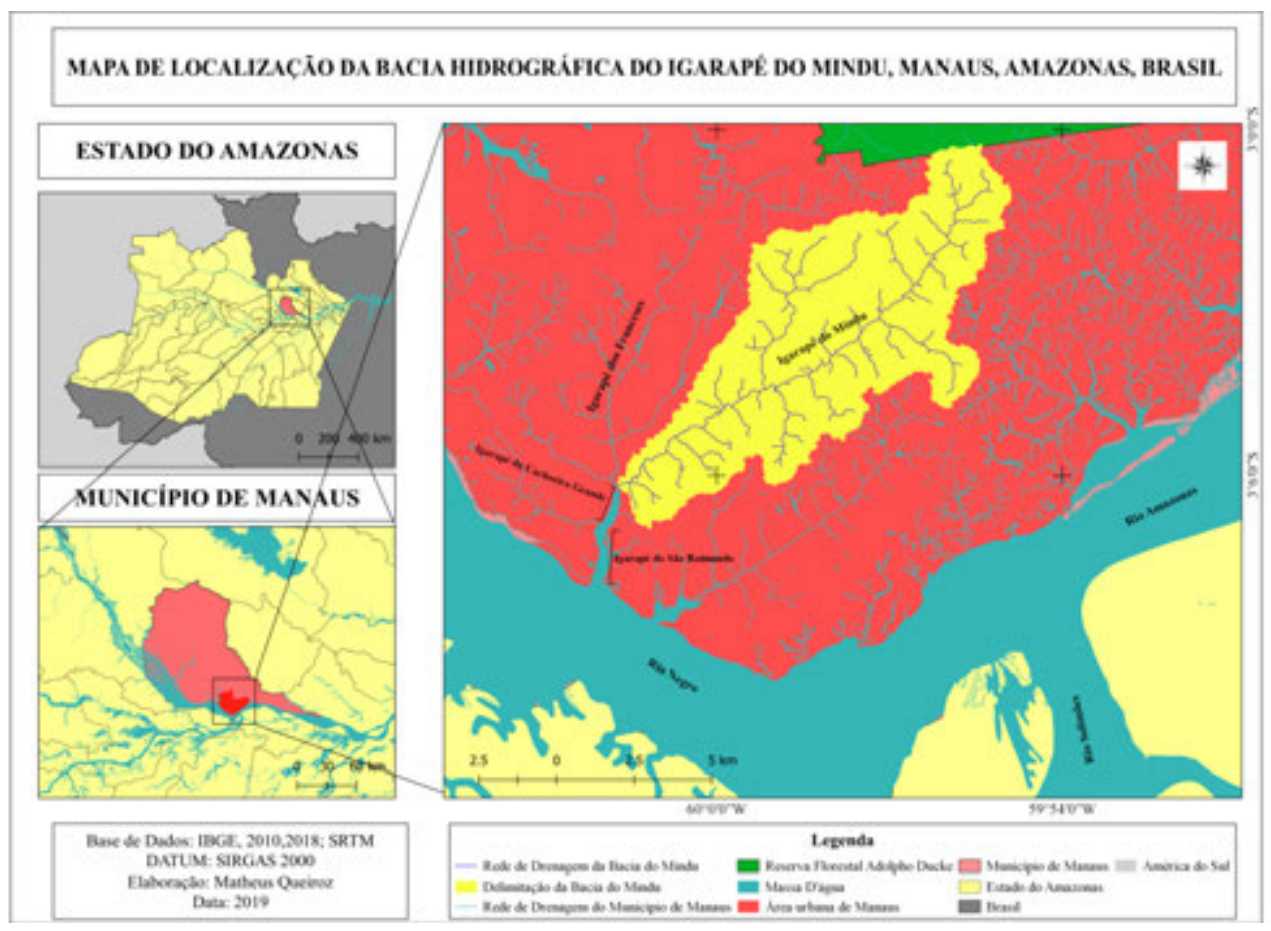

Figura 1 - Localização da bacia hidrográfica do igarapé do Mindu - Manaus Elaboração: Os autores, 2019.

O Estado do Amazonas é caraterizado, geologicamente, por uma cobertura fanerozoica que se distribui nas bacias sedimentares do Acre, Solimões, Amazonas e Marajó (REIS et al., 2006). A área de estudo está inserida na Bacia Sedimentar do Amazonas que possui aproximadamente $620.000 \mathrm{~km}^{2}$ e abrange parte dos estados do Amazonas e Pará, possuindo um formato linear alongado na direção ENE-WSW (FERREIRA et al., 2015). Essa estrutura geotectônica está encaixada entre os escudos cristalinos das Guianas, a norte, e do Brasil Central, a sul, a leste está limitada a leste pelo arco regional do Gurupá e a Bacia Sedimentar Trafogênica do Marajó e a oeste pelo arco regional do Purus e a Bacia Sedimentar do Solimões (SILVA, 2005, p. 21; REIS et al., 2006, p. 23).

Segundo Cunha et al. (2007, p. 228) a história evolutiva do embasamento précambriano, que constitui o substrato rochoso da Amazônia, está relacionada com a organização dos terrenos granitos-greenstones e dos cinturões de alto grau metamórfico, além disso ocorreu a edificação de vários baixios deposicionais, destacando-se o Gráben do Cachimbo. Quanto à origem da Bacia Sedimentar do Amazonas os autores afirmam que a origem pode estar relacionada à dispersão de esforços no fechamento do Ciclo Brasiliano.

Segundo Reis et al. (2006, p. 23) a Bacia Sedimentar do Amazonas é articulada por linhas estruturais mestres nas direções NW-SE, NE-SW e E-W que articularam sua instalação. A evolução da bacia ao longo do Fanerozoico ocorreu em função da superposição da bacia sobre as rochas do Cráton Amazônico. E "em linhas gerais, a instalação da Bacia do Amazonas respondeu pelos movimentos tectônicos do megacontinente Gondwana durante o Paleozoico e instalação de sistemas de falhas normais e de transferência na geração de arcos e discordâncias regionais" (REIS et al., 2006, p. 23). A Bacia Sedimentar do Amazonas pode ser classificada como uma bacia intracratônica e suas rochas sedimentares estão em onlap sobre 
as rochas pré-cambrianas e a sua espessura sedimentar e ígnea total atinge aproximadamente 5.000 metros de profundidade.

$\mathrm{Na}$ área da Bacia Hidrográfica do Mindu predominam sedimentos da Formação Alter do Chão do Grupo Javari. A Formação Alter do Chão foi primeiramente definida por Kistler (1954) com uma composição de arenitos avermelhados, argilitos (incluindo caulins), conglomerados e brechas intraformacionais. Essas características, normalmente, estão associadas à ambientes de deposição por sistemas fluviais, lacustres ou deltaicos. Os estratos escassamente fossiliferosos de fluvio-lacustrine da Formação Alter do Chão, representam o início do episódio sedimentar final nas bacias do Amazonas e Solimões, principalmente do Paleozoico (DINO et al., 1999). Latrubesse e Franzinelli (2005, p. 376) afirmam que as rochas sedimentares provenientes da Formação Alter do Chão na área da Bacia Hidrográfica do rio Negro datam do Cretáceo (Mesozoico).

Wanderley Filho (1991) afirma que a Bacia Sedimentar do Amazonas está estruturada sobre um segmento crustal controlado estruturalmente por falhas geológicas normais no sentido NE-SW e, posteriormente, falhas de transferência afetaram a bacia no sentido NW-SE, isso segmentou a bacia em lineamentos geológicos de drenagem que foram denominados de Manacapuru-Rio Negro, Urubu-Crepori, Faro-Juriti, Paru-Anapu e Jari-Pacajaí.

O cinturão fluvial do rio Negro apresenta um forte controle tectônico, com indícios de alinhamentos de rios, capturas, estruturas em flor, isto indica movimentos transcorrentes e sistemas de falha que afetam as estruturas morfológicas terciárias e quaternárias. Vários autores como Sternberg (1950); Latrubesse e Franzinelli (2002); Costa et al. (2008); Igreja e Franzinelli (1990a, b); Forsberg et al. (2000); Almeida Filho e Miranda (2007) se dedicaram aos estudos neotectônico na região da Bacia Hidrográfica do rio Negro.

Na região da cidade de Manaus trabalhos recentes indicam forte controle estrutural neotectônico (IGREJA, 1987; 1988; IGREJA et al., 2003; FORTES, 2001; IGREJA; FORTES, 2002; IGREJA; FRANZINELLI, 1987; IGREJA; FRANZINELLI, 1990; SILVA, 2005; SARGES, 2007; 2011; TOMAZ, 2002; SILVA, 2010; SILVA et al., 2003). Latrubesse e Franzinelli (2005, p. 378) afirmam que grandes falhas controlam o vale principal dos médio e baixo curso do rio Negro. Em sentido montante para jusante, próximo ao baixo curso, o largo vale é abruptamente separado por zonas estruturais estreitas ou pontos nodais de onde afloram rochas antigas. A grande falha que controla o vale do rio Negro segue em sentido NW-SE.

No baixo curso do rio Negro, na sua margem esquerda, existem áreas com componentes normais significativos no sentido NW-SE, ocorrendo nas margens do rio Negro falhas inferidas no sentido NW-SE, NE-SW, W-E ocorrem margeando o rio Negro e seus afluentes e falhas de deslizamento nos rios Tarumã-Açu e Tarumã-Mirim no sentido NW-SE. Sternberg (1950) já observava a possibilidade de ação neotectônica neste último. Na margem direita do rio Negro há falhas normais associadas a falhas de deslizamento e existem fraturas que originaram Half Grabens-Rombochasm no sentido NW-SE, SW-NE. Próximo à foz do rio Negro existe uma zona de contenção (LATRUBESSE; FRANZINELLI, 2005, p. 378).

Fortes (2001) e Igreja e Fortes (2002) em análise na bacia do rio Puraquequara, na Zona Leste da cidade, atribuíram à morfologia da rede de drenagem da bacia características neotectônicas, indicando que as bacias hidrográficas da região da cidade de Manaus sofrem 
ação tectônica. Silva (2005) afirma que a margem esquerda do rio Negro é formada pelo abatimento de falhas normais mestras em sentindo NW-SE com mergulho para sudoeste, o autor usa como exemplo as falhas na Avenida do Turismo, Zona Oeste da cidade, e a falha localizada na Zona Leste. Existem, também, falhas antitéticas N30W/55NE, podendo-se observar, como exemplo, a falha mapeada nas proximidades do ramal do Pau Rosa, na BR-174 que liga Manaus ao município de Presidente Figueiredo. Os estudos desenvolvidos pelos autores citados ajudam a entender a dinâmica neotectônica regional de Manaus e seus arredores.

\section{MATERIAIS E MÉTODOS}

Para fundamentar a pesquisa e validar dados foram realizadas pesquisas bibliográficas na literatura especializada e pesquisas de campo entre os anos de 2018 e 2019 para identificar indícios de neotectônica na Bacia Hidrográfica do Mindu.

Hiruma et al. (2001, p. 377) afirmam que com a interpretação de imagens de satélite, radar, cartas de sombreamento e azimutes diferenciados é possível identificar fotolineamentos, que podem indicar atividade neotectônica. Sarges $(2008$, p. 78$)$ e Sarges et al. (2011, p. 101) identificaram vários lineamentos morfoestruturais na região de Manaus e Presidente Figueiredo, no Estado do Amazonas, usando imagens de relevo sombreado com iluminação de $45^{\circ}$ e azimutes NE e SE. Silva $(2005$, p. 123) identificou, também na região de Manaus, lineamentos morfoestruturais e de drenagem a partir de cartas topográficas e modelos digitais de elevação. Neste trabalho, optou-se pela utilização da metodologia proposta por Sarges (2008).

Para a realização dos mapeamentos de lineamentos na Bacia Hidrográfica do igarapé do Mindu foram usadas imagens de radar do satélite Alos Palsar disponibilizadas pelo site do Vertex (Alaska Satellite Facillity) (https://www.asf.alaska.edu). O satélite possui resolução espacial de 12,5 metros.

Silva (2005, p.143) afirma que a análise de basculamentos na bacia indica interferência tectônica na evolução da rede de drenagem. $O$ autor apresenta a seguinte fórmula para a quantificação dos basculamentos (Equação 1):

$$
A F=100\left(\frac{A_{d d}}{A_{d}}\right)
$$

Onde:

$\mathrm{AF}=$ Fator de Assimetria (Asymmetric Factor)

$A d d=E$ E área de drenagem da margem direita da bacia (sentido jusante)

$A d=$ É a área de drenagem total da bacia

Quando o valor de $A F=50$ a bacia é simétrica, para valores de $A F>50$ a bacia sofreu basculamento para a esquerda e com valores de $A F<50$ a bacia sofreu basculamento para a direita. Considera-se sempre na análise dos dados o sentido montante-jusante. 
Sternberg (1950) afirma que canais retilíneos em conjunto com fatores morfológicos podem indicar atividade neotectônica. Portanto, para definir e quantificar o tipo de canal, com base no índice de sinuosidade em tortuosos, irregulares, regulares, transicionais e retos, foi utilizada a classificação de Schumm (1963), os resultados foram interpretados a partir do Quadro 1. A fórmula para determinar o índice de sinuosidade é apresentada na equação 2:

$$
I_{s}=\frac{C_{c}}{E_{v}}
$$

Onde:

$I_{S}=$ É o índice de sinuosidade

$C_{c}=$ É o comprimento real do Canal

$E_{v}=$ É a distância entre a nascente e a foz em linha reta.

Quadro 9 - Classificação de canais de Schumm (1963)

\begin{tabular}{|l|r|}
\hline Tipos: & Valor do índice \\
\hline A) Meandrantes: & 2,3 \\
\hline a) Tortuosos & 1,8 \\
\hline b) Irregulares & 1,7 \\
\hline c) Meandros Regulares & 1,3 \\
\hline B) Transicionais & 1,1 \\
\hline C) Retos & \\
\hline
\end{tabular}

Fonte: Christofoletti, 1981.

\section{RESULTADOS E DISCUSSÕES}

A configuração geomorfológica atual da região de Manaus é resultado das mudanças morfoestruturais ocorridas na rede de drenagem da região Amazônica, possivelmente durante o Paleogeno, observa-se que os lineamentos e alinhamentos morforestruturais da região de Manaus possuem relação direta com a evolução da rede de drenagem (HOORN et al., 1995; MAPES et al., 2006; SARGES, 2008). A delimitação do lineamento presente na bacia do igarapé do Mindu foi realizada utilizando como base o relevo sombreado da bacia (Figura 2a). Dessa forma foi possível delimitar tanto o lineamento que predomina na bacia, quanto a sua morfologia de forma e sua direção (Figura 2b).

O lineamento localizado na Bacia Hidrográfica do Mindu tem direção NE-SW sendo que este é ligeiramente curvo. Sarges (2008) e Sarges et al. (2011) identificaram também dentro da Bacia Hidrográfica do São Raimundo, na qual a bacia do Mindu está inserida, lineamentos também nos igarapés dos Franceses e do São Raimundo. Analisando a sinuosidade o canal em conjunto com a geomorfologia Sternberg (1950) afirma que os canais retilíneos da bacia podem indicar influência neotectônica na morfologia da rede de drenagem. $O$ igarapé do Mindu possui um índice de sinuosidade de 1,1, sendo considerado um canal retilíneo, isto em 
conjunto com o lineamento morfoestrutural, pode indicar um controle tectônico na área da bacia.

Figura 2 a, b - Relevo sombreado e Lineamento Morfoestrutural na bacia hidrográfica do Mindu
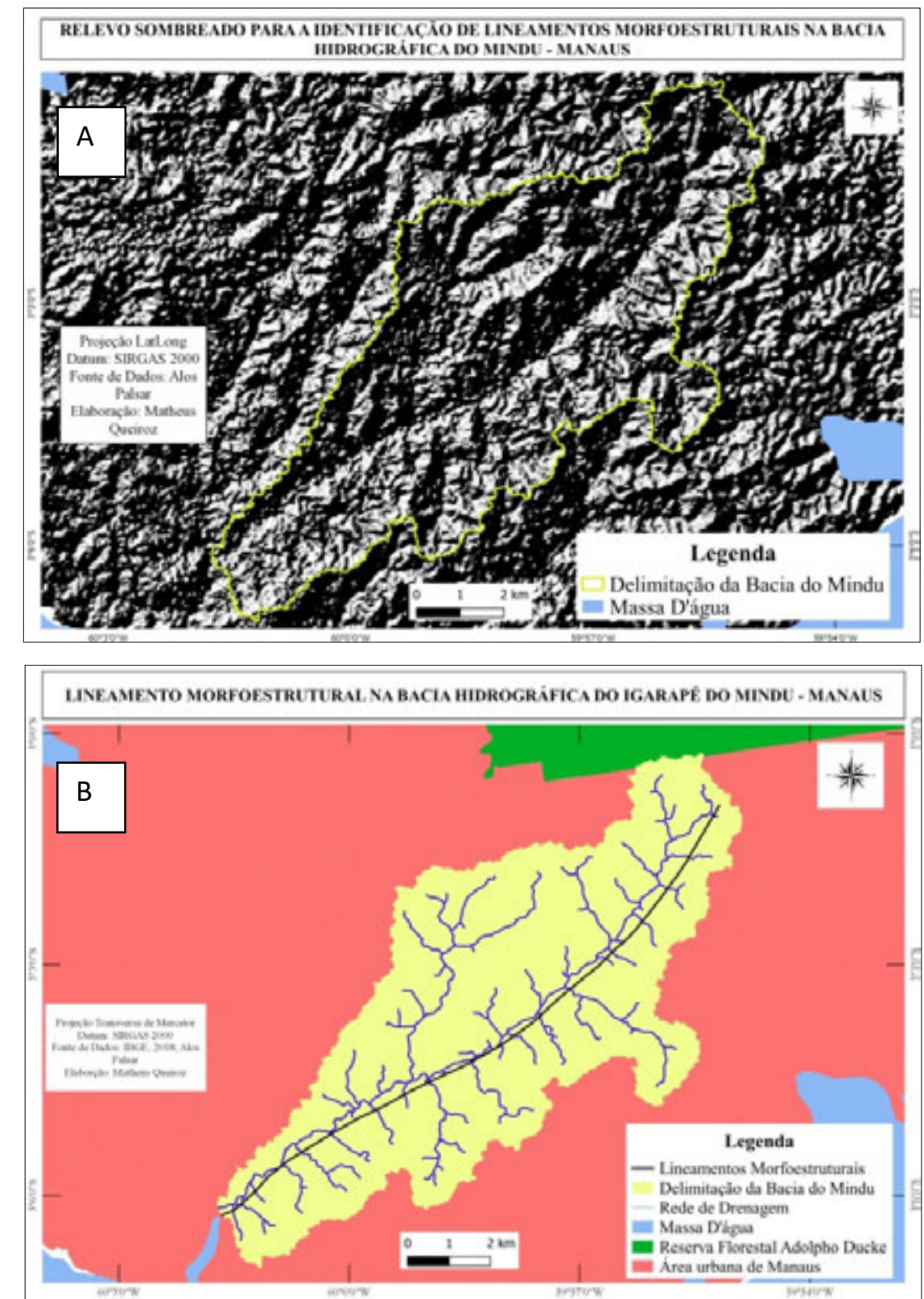

Elaboração: Os autores, 2019.

Stevaux e Latrubesse (2017) afirmam que os tipos de padrão de rede de drenagem possuem relação com a geologia ao qual a bacia hidrográfica está submetida. Tomas e Goudie (2000) classificam os tipos de padrão quanto: a) ao substrato geológico; b) a geologia estrutural regional; c) a história geomorfológica da área em questão. A Bacia Hidrográfica do Mindu possui um padrão de drenagem dendrítico. Schumm et al. (2000) afirma que esse padrão está relacionado ao tipo de substrato geológico, ou seja, de acordo com a rocha (sedimentar horizontal ou uniforme ou cristalina) e a estrutura. A Bacia Hidrográfica do Mindu drena rochas sedimentares da Formação Alter do Chão. 
Howard (1967) afirma que a análise de anomalias na rede de drenagem é importante para determinar se há influência tectônica na bacia hidrográfica, e se essas anomalias podem ser drenagem colinear (BISHOP, 1995), captura fluvial (SCHUMM et al., 2000; SUMMERFIELD, 1991; BISHOP, 1995), desvio de rios (BISHOP, 1995), bacia assimétrica (SILVA, 2005), inflexões abruptas e curvas anômalas (HOWARD, 1967), ou decapitação (beheading) (BISHOP, 1995).

No caso da Bacia Hidrográfica do Mindu é possível identificar curvas anômalas e assimetria, indicando basculamento tectônico. Howard (1967) afirma que as curvas anômalas possivelmente indicam inversão de relevo ou então de marcante controle estrutural. As curvas são notadas com maior frequência nos afluentes do igarapé do Mindu e no baixo curso do mesmo.

Outro fator para entender a influência neotectônica na bacia é a análise quantitativa de basculamento que é importante para identificar se a rede de drenagem de uma bacia hidrográfica sofreu influência neotectônica ao longo da sua formação morfológica (SILVA, 2005; FIRMINO, 2018). O Fator de Assimetria (Asymmetric Factor) da bacia hidrográfica do Mindu é de 46,8, isso significa que a bacia sofreu basculamento tectônico para direita, influenciando na morfologia de sua rede de drenagem. Silva (2005) analisou as bacias hidrográficas dos rios Tarumã-Açú, Tarumã-Mirim, Preto da Eva, Urubu e Cuieiras e determinou que todas as bacias, com exceção da bacia do Tarumã-Mirim cujo basculamento foi para a esquerda, sofreram basculamento para a direita. Isto indica uma migração do canal principal em sentido SE-NO.

No baixo curso do igarapé do Mindu ocorre um knickpoint (Figura 3) com altura (h) máxima de 1,68 metros. Essas formas geomorfológicas são "degraus" topográficos no relevo e podem ter origem em diversos fatores como erosão diferencial no nível de base (SILVA, 1993), por características sedimentodológicas dos canais fluviais, capturas de drenagem, litologia e atividade tectônica (MARTINS, 2012).

Figura 3 - Knickpoint no baixo curso do igarapé do Mindu

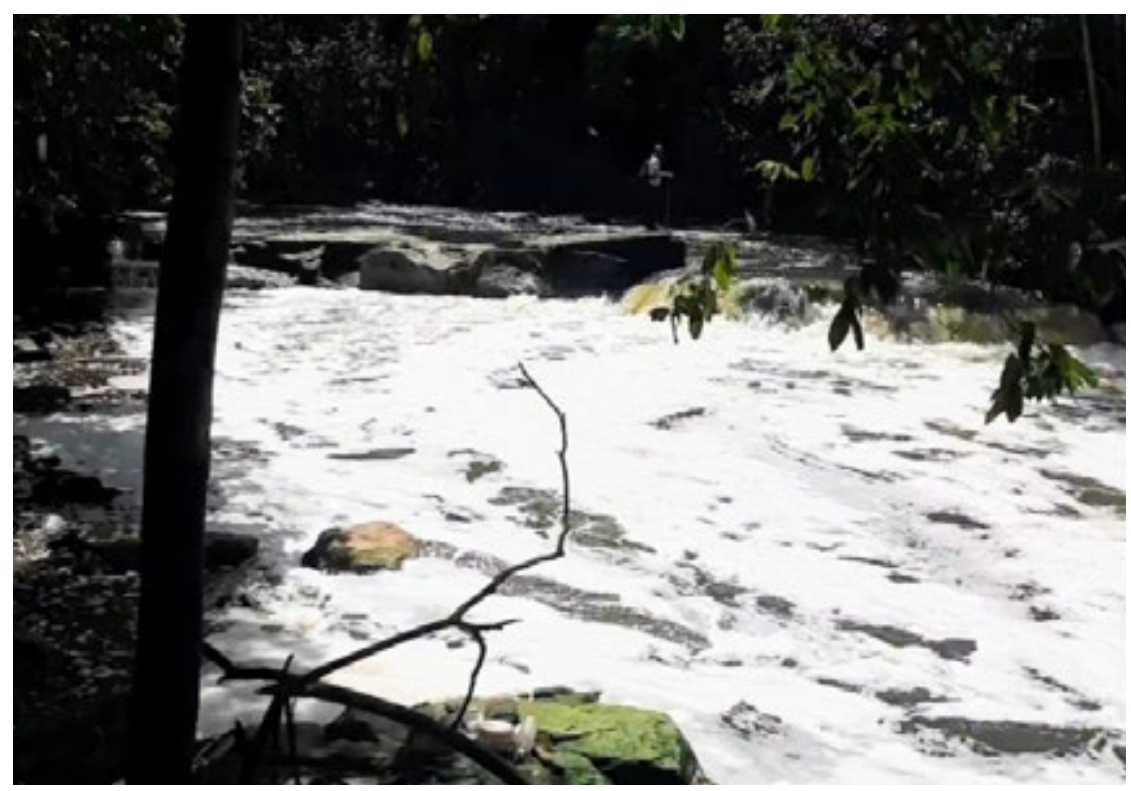

Foto: Os autores, 2019. 
Morisawa (1968) afirma que os knickpoint podem estar associados na sua gênese a terremotos, indicando tectonismo, pois movimentos tectônicos normalmente estão associados à sismicidade. Sternberg (1955) aprofunda a discussão iniciada em Sternberg (1950) sobre a atividade sísmica na região Amazônica como um importante fator de evolução do relevo, observa-se alinhamentos e lineamentos que possivelmente estavam associados a falhas geológicas na região da cidade Manaus, apontando a relação direta dessas estruturas com a rede de drenagem da região Amazônica. Costa et al. (1996) e Mioto (1993) afirmam que a região de Manaus, mais especificamente nas imediações da confluência dos rios Negro e Solimões, é uma zona de epicentro sismológico. Analisando os fatores neotectônicos na bacia do Mindu, coloca-se como possibilidade a ação tectônica na gênese do knickpoint do igarapé do Mindu.

\section{CONSIDERAÇÕES FINAIS}

Analisando os fatores neotectônicos de lineamentos e basculamento da Bacia Hidrográfica do Mindu é possível afirmar, usando como base os dados obtidos e a literatura disponível, que a bacia foi submetida à atividade neotectônica, possivelmente durante o cenozoico. Isso impactou na morfologia da rede de drenagem como um todo e, principalmente, no padrão do canal principal da bacia, o igarapé do Mindu.

É possível identificar um lineamento morfoestrutural que controla a morfologia do canal principal da bacia do Mindu; anomalias na bacia mostram basculamento tectônico para direita, indicando um rearranjo da rede de drenagem; curvas anômalas que podem indicar neotectonismo. A presença de um knickpoint e de registros na literatura de evento sísmicos na área da bacia também podem indicar atividade neotectônica. É necessário, para trabalhos futuros, um maior aprofundamento dos dados obtidos, principalmente de um maior detalhamento do lineamento encontrado e da morfogênese do knickpoint para melhor entender qual o grau de neotectonismo que a Bacia Hidrográfica do Mindu foi submetida ao longo da sua história evolutiva.

\section{REFERÊNCIAS}

1. ALMEIDA FILHO, R.; MIRANDA, F. P. Mega capture of the Rio Negro and formation of the Anavilhanas Archipelago, Central Amazônia, Brazil: Evidences in an SRTM digital elevation model. Remote Sensing of Environment, v. 110, p. 387-392, 2007.

2. BISHOP, P. Drainage rearrangement by river capture, beheading and diversion. Progress in PhysicalGeography ,19 (4):449-473, 1995.

3. COSTA, J. B. S.; BEMERGUY, R. L.; HASUI, Y. ; BORGES, M. S ; FERREIRA JÚNIOR, C. R. P. ; BEZERRA, P. E. L.; COSTA, M. L.; FERNANDES, J. M. G. Neotectônica Da Região Amazônica: Aspectos Tectônicos, Geomorfológicos E Deposicionais. Geonomos, Belo Horizonte, v. 4, n. 2, p. 23-44, 1996.

4. COSTA, R.C.R; NATALI FILHO, T. e OLIVEIRA, A.A.B.de. Geomorfologia. IN: Projeto RADAMBRASIL. Folha SA 20 - Manaus. Rio de Janeiro: DNPM. p. 165- 244. 1978. 
5. CUNHA, P.R.C.; MELO, J.H.G.; SILVA, O.B. Bacia do Amazonas. B. Geoci. Petrobras, Rio de Janeiro, v. 15, n. 2, p. 227-251, 2007.

6. DINO R.; SILVA, O.B.; ABRAHÃO, D. Palynological and stratigraphic characterization of the Cretaceous strata from the Alter do Chão Formation, Amazonas basin. In: UNESP, Simpósio sobre o Cretáceo do Brasil and Simpósio sobre el Cretácico de América del Sur, 5, Anais, p. 557-565, 1999.

7. FERREIRA, A.; RIGUETI, A.; BASTOS, G. BACIA DO AMAZONAS: Sumário Geológico e Setores em Oferta. 13a Rodada de Licitações de Petróleo e Gás. 17 p. Acesso em: 11/09/2018. Disponível. em: http://rodadas.anp.gov.br/arquivos/Round_13/areas_oferecidas _r13/Sumarios_Geologicos/Sumario_Geologico_Bacia_Amazonas_R13.pdf, 2015.

8. FIRMINO, I.G. Índices Indicativos De Basculamento Tectônico: A Relação Entre A Assimetria De Bacias E Assimetria De Vales Para Rios Encaixados. In: XXI SINAGEO, Crato CE, 2018.

9. FORSBERG, B., HASHIMOTO, Y., ROSENQVIST, A., MIRANDA, F.P. Tectonic fault control of wetland distributions in the central Amazon revealed bi JERS-1 radar imagery. Quaternary International, 72, 2000, pp. 61-66.

10. FORSBERG, B., HASHIMOTO, Y., ROSENQVIST, A., MIRANDA, F.P. Tectonic fault control of wetland distributions in the central Amazon revealed bi JERS-1 radar imagery. Quaternary International, 72, 2000, pp. 61-66.

11. FORTES, M.R. Diagnóstico morfodinâmico aplicado ao planejamento ambiental na Microbacia hidrográfica do rio Puraquequara. Dissertação (Programa de Pós Graduação em Sociedade e Cultura da Universidade federal do Amazonas - UFAM), 2001.

12. HIRUMA, S.T.; RICCOMINI, C.; MODENESI-GAUTTIERI, M.C. Neotectônica no Planalto de Campos do Jordão, SP. Revista Brasileira de Geociências, 31, pp.374-384, 2001.

13. HOORN, C.; GUERRERO, J.; SARMIENTO, G.; LORENTE, M. Andean Tectonics as a cause for a changing drainage patterns in Miocene northern South America. Geology, 23, pp. 237-240, 2007.

14. HOWARD, A. D. Drainage analysis in geologic interpretation: a summation. In: AMERICAN ASSOCIATION OF PETROLEUM GEOLOGIE BULLETIM, 51(11) : 2246- 2259, 1967.

15. IBGE - Instituto Brasileiro de Geografia e Estatística. Cidades. Disponível em: https://cidades.ibge.gov.br/. Acesso em: Junho de 2019.

16. IGREJA, H. Aspectos do Modelo Neotectônico da Placa Sul-Americana na Província Estrutural Amazônica, Brasil. Tese (Acesso à classe de professor titular) - Universidade Federal do Amazonas - UFAM, Manaus, 1988. 
17. IGREJA, H. Neotectônica: O lineamento Rio Negro, um exemplo na Região. Boletim do ICE/UA, n. 4, 1987.

18. IGREJA, H.; FRANZINELLI, E. Utilização de sensoriamento remoto na investigação na área do baixo rio Negro e Grande Manaus. In: Anais do Vi Simpósio Brasileiro De Sensoriamento Remoto, 6, Manaus, 1990.

19. IGREJA, H.; FRANZINELLI, E.; MELO, A.P. Analysis of Geologic Joints and Their Relationship with Geomorphologic Features Risk of Greater Manaus, Amazonas State, Brazil. In: Annals Of Geomorphic Hazards: Toward The Prevetion Of Disasters. The International Association Of Geomorphologists And Mexican Society Of Geomorphology Conference, City Of Mexican, 2003.

20. IGREJA, H.L.S., FRANZINELLI, E. Estudos neotectônicos na região do baixo Rio Negrocentro-nordeste do Estado do Amazonas. In: Congresso Brasileiro de Geologia, 36, 1990, Manaus. Anais... Manaus: SBG/NO, 1990, v. 5, p. 2099-2108.

21. IGREJA, H.L.S; CARVALHO, J.A.L.; FRANZINELLI, E. Aspectos das Terras Caídas na Região Amazônica. In: ALBUQUERQUE, A.R. (Org.). Contribuições Teórico-Metodológica da Geografia Física. EDUA: Manaus, 2010.

22. IGREJA, H.L.S; FORTES, M.R. Geomorfologia Tectônica da Micro-Bacia do Puraquequara, Cidade de Manaus - Estado do Amazonas. In Anais do Congresso Brasileiro de Geologia, 41, Paraíba, 2002.

23. KISTLER, P. Historical Resumé of the Amazon Basin. Belém, PETROBRAS-RENOR, (Relatório Técnico Interno, 104-A), 1954.

24. LATRUBESSE, E., FRANZINELLI, E. The holocene alluvial plain of the middle Amazon river, Brazil. Geomorphology, v. 44, p. 241-57, 2002.

25. LATRUBESSE, E.M; FRANZINELLI, E. The late Quaternary evolution of the Negro River, Amazon, Brazil: Implications for island and floodplain formation in large anabranching tropical systems. Geomorphology 70, 2005, 372-397.

26. MAPES, R.W. NOGUEIRA, A.C.R.; COLEMAN, D.S.; VEJA, A.M.L.; Evidence for a continente scale drainage invension in the Amazon Basin since de Late Cretaceous. In: GSA Philadelphia Annual Meting, 2006.

27. MARTINS, A; CALDEIRA, B; BORGES, J. "Transient Knickpoints" No Leito Dos Rios, Significado Na Evolução Da Paisagem. In: SILVA, A.M; ARAÚJO, A.A; REIS, A.H; MORAES, M; BEZZEGHOUD, M. Two Decades of earth science research. University of Évora, 2012.

28. MORISAWA, M.E. Strems: Their dynamics and morphology. McGraw-Hill Book, New York, 1968. 
29. MÖRNER, N.A. Neotectonics, the new global tectonic regime during the last $3 \mathrm{Ma}$ and the initiation of Ace Ages. Anais da Academia Brasileira de Ciências, v. 65, pp. 295-301, 1993.

30. OBRUCHEV, V.A. Osnovnye Cherty Kinetiki i Plastiki neotektoniki. Akademia Nauk SSSR, Izveytiya Seriya Geologiya, 1948.

31. QUEIROZ, M.S.; BATISTA, S.P.M.; TOMAZ NETO, A.G.; ALVES, N.S. Expedição Mindu: Análise Geográfica Do Igarapé Do Mindu. In: VII Workshop Internacional Sobre Planejamento E Desenvolvimento Sustentável Em Bacias Hidrográficas, Manaus, 2019a, no prelo.

32. SARGES, R.R. Relações entre as estruturas tectônicas, sedimentação coluvial e geomorfogênese da região de Manaus, Amazonas. 109f. Tese (Doutorado em Geociências), Universidade de São Paulo, São Paulo, 2008.

33. SARGES, R.R.; SILVA, T.M.; RICCOMINI, C. Caracterização Do Relevo Da Região De Manaus, Amazônia Central. Revista Brasileira de Geomorfologia - v. 12, no 1, 2011.

34. SILVA, C.L. Análise Da Tectônica Cenozóica Da Região De Manaus E Adjacências. Tese (Programa de Pós-Graduação em Geociências Da Universidade Estadual Paulista UNESP Rio Claro), 2005.

35. STERNBERG, H.O. Séismicité et morphologie en Amazonie brésilienne. Annales de Géographie, 342, pp. 97-105, 1955. Disponível em: https://www.persee.fr/doc/geo_00034010_1955_num_64_342_14883. Acesso em: 12/11/2019.

36. STERNBERG, H.O. Vales Tectônicos na Planície Amazônica?. Revista Brasileira de Geografia, n. 4, 1950.

37. STEVAUX, J.C; LATRUBESSE, M. E. Geomorfologia Fluvial. Oficina de Textos: São Paulo: 2017.

38. SUGUIU, K. Geologia do Quaternário e Mudanças Ambientais. São Paulo: Oficina de Textos, 2010.

39. SUMMERFIELD, M. A. Global Geomorphology. New York: Jonh Wiley e Sons, p. 537, 1991.

40. VITA-FINZI, C. Recent earth movements: an introduction to neotectonics. London: Academic Press, 1986.

41. WANDERLEY FILHO, J.R. Evolução estrutural da Bacia do Amazonas e sua relação com o embasamento. Dissertação de Mestrado, Centro de Geociências, Universidade Federal do Pará. 125 p, 1991. 